\title{
How a small accelerator can be useful for interdisciplinary applications: the study of air pollution
}

\author{
Franco Lucarelli ${ }^{\mathrm{a}}$ \\ Department of Physics and Astronomy, University of Florence and National Institute of Nuclear Physics \\ (INFN), Via Sansone 1, 50019 Sesto Fiorentino, FI, Italy
}

Received: 1 April 2020 / Accepted: 7 June 2020 / Published online: 2 July 2020

(C) The Author(s) 2020

\begin{abstract}
There are an increasing number of articles in the scientific literature dealing with the study of atmospheric aerosol because it has negative impacts on human health, atmospheric visibility and a role in the radiative forcing. Particle-induced X-ray emission (PIXE) has been used since its birth for the study of the aerosol composition, and for a long time, it has been the dominating technique for its elemental analysis. However, nowadays other competitive techniques play a dominant role, such as inductively coupled plasma-mass/atomic emission spectroscopy, energy-dispersive X-ray fluorescence and synchrotron radiation. Therefore, it is important to find specific applications where it can give unique information or the final results in a far simpler way. Furthermore, a proper experimental setup must be used to fully exploit the potential of PIXE. Thanks to the capability of detecting all the crustal elements, PIXE analyses are unrivaled in the study of mineral dust. Among the detectable elements, there are also important markers of anthropogenic sources, which allow effective source apportionment studies in polluted urban environments using multivariate methods. Examples regarding recent monitoring campaigns will be presented to show how PIXE is still on the cutting edge for the study of particulate matter.
\end{abstract}

\section{PIXE technique}

The presence of atmospheric aerosols or particulate matter (PM) in the atmosphere impacts the environment by the reduction in the visibility, formation of clouds, effecting heat transfer in the atmosphere, thereby contributing to the climate change [1, 2]. For the development of effective PM abatement strategies, it is necessary to identify and quantify the PM sources. It is fundamental to understand what is the part and what is the impact of anthropogenic activities on climate, to reconstruct the past atmospheric concentration of mineral dust to correlate its variations with climatic change.

Among the employed techniques, those based on the use of 'small' particle accelerators are largely used for elemental analysis. In particular, the particle-induced X-ray emission (PIXE) technique has been widely used since its birth for the study of the aerosol composition. For a long period, it has been the dominating technique for its elemental analysis [3,4] because

\footnotetext{
a e-mail: lucarelli@fi.infn.it (corresponding author)
} 
up to 20 elements (from $\mathrm{Na}$ to $\mathrm{Pb}$ ) including important anthropogenic elements $(\mathrm{S}, \mathrm{V}, \mathrm{Ni}$, $\mathrm{Cu}, \mathrm{Zn}, \mathrm{As}$ and $\mathrm{Pb}$ ) and all the crustal elements ( $\mathrm{Al}, \mathrm{Si}, \mathrm{K}, \mathrm{Ca}, \mathrm{Ti}, \mathrm{Mn}$ and $\mathrm{Fe}$ ) can be detected in only few minutes. However, nowadays there are other competitive techniques such as inductively coupled plasma-mass spectroscopy (ICP-MS) [5], inductively coupled plasma-atomic emission spectroscopy ICP-AES) [6], energy-dispersive X-ray fluorescence (ED-XRF) [7] and synchrotron radiation (XRF SR-XRF) [8] which play a dominant role. Therefore, specific applications where PIXE can give unique information or the final results in a far simpler way with respect to other competing techniques must be found for a successful use of it.

PIXE technique can continue to provide an invaluable contribution to atmospheric aerosol research since it has many advantages for elemental analysis of aerosols [3,4]. One is the very short measuring time, about $60 \mathrm{~s}$ versus $1 \mathrm{~h}$ for typical ED-XRF analysis. ICP techniques have the analysis time only a little longer, but ICP methods need long times for sample preparation. This can be a crucial aspect in the analysis of thousands or hundreds of samples collected in big sampling campaigns. PIXE gives data for major, minor and trace elements. The data for the major elements $(\mathrm{S}, \mathrm{Na}, \mathrm{Cl}, \mathrm{Al}, \mathrm{Si}$ and $\mathrm{Fe}$ ) are necessary for the determination of the contributions of important aerosol types (e.g., sea salt and crustal material) and for the achievement of the chemical mass closure. Furthermore, multi-elemental data set as a whole (which comprises data for various anthropogenic tracers) is used for disentangling the contributions from different source categories by applying multivariate receptor modeling [9].

It is possible to analyze samples with very low mass such as those collected with high time (e.g., $1 \mathrm{~h}$ ) or size resolution (e.g., streakers [10] and small deposit area low-pressure impactors (SDI) [11]). Usually, PM is collected with a 24-h time resolution. However, many particulate emissions change within a few hours (construction works, industrial or traffic emissions, etc.); moreover, the boundary layer evolution shows strong diurnal patterns and many meteorological parameters, like wind intensity and direction, change within a 1-h timescale. Consequently, the aerosol composition and concentration may significantly change within a few hours and daily samples are not capable to track these rapid changes. Therefore, the measurement of the PM composition with high time resolution is important to assess health and environmental effects, to understand transport processes and to determine source contributions.

On a global scale, mineral dust (coming, e.g., from the Saharan desert) together with sea salt particles are dominant. It influences the earth system through the interaction with the radiation, its role in the cloud formation and the fertilization of the ocean, which influences $\mathrm{CO}_{2}$ absorption. Furthermore, it can episodically increase significantly the PM levels in urban areas. Therefore, good data on the composition and concentration of mineral aerosol are necessary. PIXE detects easily with good accuracy all the soil-related elements [12]. (The sample mineralization by concentrated HF prevents the determination of Si by ICP, one of the most relevant crustal markers.) No sample preparation or extraction is necessary; therefore, the contamination from chemical reagents and the possible loss of volatile elements in the sample are reduced compared to ICP-MS. This is fundamental for very low mass samples (e.g., remote sites aerosol) [13].

PIXE has sensitivities typically one order of magnitude better compared to those of traditional ED-XRF and needs far shorter measuring times even with samples with very low mass. Finally, further measurements with other complementary techniques can be taken (not on organic compounds) because PIXE is a nondestructive analytical technique, or it can be complemented by other ion beam analysis techniques like particle-induced $\gamma$-ray emission (PIGE) [14]. 
A proper experimental setup is necessary to exploit completely the benefits of PIXE in the analysis of aerosol samples.

Finally, it must be considered that PIXE gives only part of the desired information on the chemical composition; it is also mandatory to measure important ionic species (e.g., ammonium, nitrate, organic carbon and elemental carbon). The application of multivariate receptor modeling for aerosol source apportionment with PIXE data alone can lead to wrong results [15]; therefore, aerosol research exclusively based on PIXE often is not sufficient even if it continues providing an invaluable contribution to atmospheric aerosol research.

Indeed, the very basic principles and possibilities of PIXE in the field of aerosol science are themselves sometimes not entirely known outside the small community of the specialized physicists. It can be worthwhile, therefore, to briefly recall preliminarily what one is dealing with.

The first part of the article will be devoted to the description of the PIXE technique and of the nature, origin and effects of atmospheric aerosol; then, the description of a proper experimental setup and of the experimental procedures adopted depending on the different kinds of samples to be analyzed (e.g., the choice of the optimal measurement parameters like the beam energy) for PIXE analysis of aerosol samples will be discussed. Finally, some examples of typical applications will be presented to show how, compared to other competing techniques, those based on ion beam analysis techniques like PIXE are still on the cutting edge for the study of particulate matter.

\section{PIXE technique}

\subsection{General features}

The PIXE technique belongs to the category of the ion beam analysis (IBA) techniques and is perhaps the most widely used among them. It is a technique for the elemental analysis of a sample, which is used as a target for the bombardment with a beam of accelerated particles; the interactions of the beam particles with the target atoms lead to the emission of X-rays of characteristic energies, through the detection of which the target composition can be deduced. In this technique, protons are almost universally chosen to induce X-ray emission. The method makes it possible to detect simultaneously and with great sensitivity almost the full range of elements present in the analyzed sample. In practice, some limitations partially restrict the number of detectable elements, but the multi-element capability is actually retained to a very large extent. As a rule of thumb one might state that in a single measurement-typically lasting few minutes - all elements with $Z>10$ are detected with minimum detection limits (MDLs) down to trace levels. The X-rays emitted by the lower- $Z$ elements have such a low energy that are absorbed in the entrance window of the detector.

\subsection{In-depth review of the technique}

The working principle of PIXE is quite simple. Using a small (usually electrostatic) accelerator, a beam of particles is produced with an energy of typically $2-3 \mathrm{MeV}$. The beam particles, when impinging on a target, interact with atoms and nuclei of the target itself; in particular, the inner shells of the target atoms may be ionized. The inner shell vacancy is promptly filled (within a time interval of the order of $10^{-15} \mathrm{~s}$ ) by an outer electron, and the difference $\Delta E=$ $E_{\mathrm{o}}-E_{\mathrm{i}}$ of the electron binding energies $E_{\mathrm{o}}$ and $E_{\mathrm{i}}$ in the outer and inner shell is released. One of the processes through which the energy $\Delta E$ can be released is just the emission of 

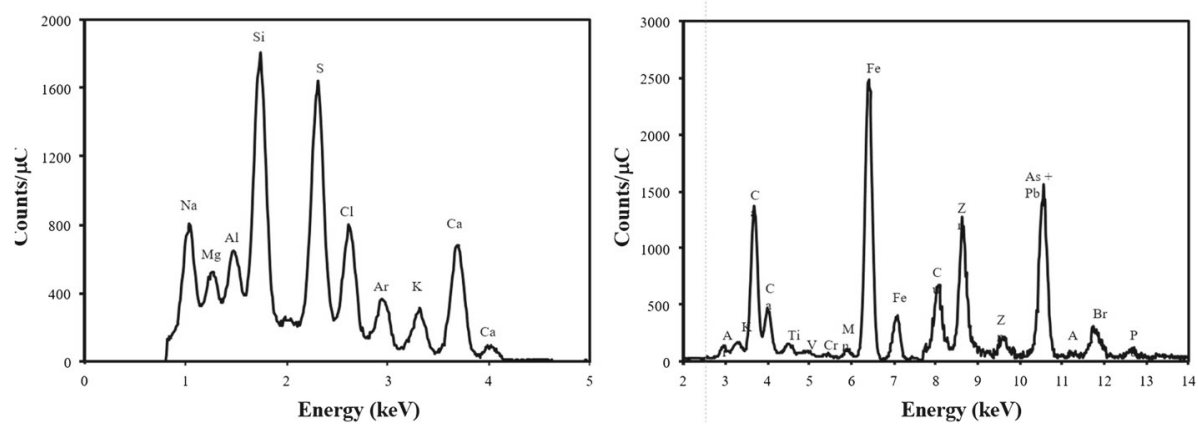

Fig. 1 PIXE spectra of a $\mathrm{PM}_{10}$ sample on Teflon collected in an industrial area taken by a two-detector system (see Sect. 3). Proton beam energy $2.2 \mathrm{MeV}$, beam current $6 \mathrm{nA}$

an X-ray of that energy. A competing mechanism (the Auger effect) is the energy transfer to another electron of an outer shell, which is consequently ejected with a kinetic energy $E_{\mathrm{k}}=$ $\Delta E-E_{j}$, where $E_{j}$ is the binding energy of the electron to which $\Delta E$ is transferred.

The energy of the emitted X-ray is clearly characteristic of the emitting atomic species, being the difference of electron binding energies that are indeed characteristic of the atomic species. Thus, the energy spectroscopy of the X-rays from the sample during particle beam bombardment provides an analysis of its composition. Such an analysis is multi-elemental, because all the atomic species present in the target undergo interactions with the beam particles, and therefore emit characteristic X-rays. It is also quantitative, because during an irradiation the number of interactions of the beam particles with the atoms of a given species is proportional to the abundance of atoms of that species in the target. The analysis is also totally nondestructive, because the beam particle-target atom interactions do not produce significant alterations in the target and involve only a tiny fraction of the target atoms. The possibility of further analysis (by the same or different techniques) is guaranteed for the same sample.

The possibility of performing PIXE while keeping the sample in the atmosphere (nonvacuum or external PIXE) makes it a very versatile technique (see below). All kinds of samples may be quantitatively analyzed: solid, gaseous or liquid (the latter two with an external beam). Elemental mapping may also be performed by scanning the beam on the sample during analysis (or moving the sample under the beam).

In PIXE, the detection and discrimination of X-rays emitted under beam bombardment are usually performed through the use of solid-state $\mathrm{Si}(\mathrm{Li})$ detectors, much less frequently, hyperpure Ge detectors, or, more recently, of SDD detectors, which discriminate the different $\mathrm{X}$-rays by their different energies. To give an idea of the kind of information collected, Fig. 1 shows two typical X-ray spectra obtained with SDD detectors in a PIXE measurement of an aerosol sample.

There are several physical reasons for the presence of the continuous background in the PIXE spectra. In the lower-energy part, the continuous spectrum is higher and arises mainly from atomic electrons ejected by the interactions of the beam particles with the target. During their stopping down within the target, these electrons emit Bremsstrahlung radiation. Some background continuum exists even in the higher-energy part of the PIXE spectrum. It originates mainly from the Compton interactions of the higher-energy gamma 
rays produced by the incident particles either in the target or in other materials before hitting the target (collimators, exit window in the external beam setup, etc.).

Comprehensive descriptions of the theoretical basis of the technique are available in [16, 17].

\subsection{Quantitative PIXE analysis}

The proton interactions with the inner shell electrons of the target atoms produce ionizations. The number of ionizations $N_{\text {ion, } j}(Z)$ produced in a given shell $j(j=K, L, M$, etc.) for a given atomic species $Z$ in the target is proportional to the target concentration of that atomic species, to the number of particles $N_{\mathrm{p}}$ having passed through the target and to the thickness $t$ of the sample (Eq. 1):

$$
N_{\text {ion, }, j}(Z)=\sigma_{\text {ion, } j} N_{Z} t N_{\mathrm{p}}
$$

where $N_{Z}$ is the number of atoms of atomic number $Z$ per unit volume. The term $\sigma_{\text {ion }, j}$ is the ionization cross section for the given shell $j$. As shown in Eq. (1), it has the physical dimensions of an area and is a measure of the probability of the interaction giving rise to the specific ionization. Except for the case of the $K$ shell, ionization cross sections are made up of more terms, corresponding to ionizations of the various subshells, for instance $\sigma_{\mathrm{L} 1}$, $\sigma_{\mathrm{L} 2}$, and $\sigma_{\mathrm{L} 3}$.

The trend of $\sigma_{\text {ion, } K / L / M}$ has a strong decrease with increasing $\mathrm{Z}$ and a strongly increasing trend with increasing $E_{\mathrm{p}}$ within the range of proton bombarding energies usually adopted. The cross section reaches a maximum when the projectile velocity matches that of the ejected electron. Further increase in the projectile energy results in a slow decrease in cross section. The increase with Ep is larger for higher values of $\mathrm{Z}$ so that, in general, working at higher energies makes the analysis of heavier elements comparatively more sensitive.

The nomenclature for X-rays emitted as a consequence of an outer electron transition following inner shell ionizations recalls both the primary vacancy location and the filling electron provenance. These are referred to as $K$-series, $L$-series, $M$-series, etc. X-rays, depending on the initially ionized shell. Within each series, the further specification is then related to the provenance shell of the electron. $K_{\alpha}$ and $K_{\beta}$ X-rays correspond to the fill $K_{\alpha 2}, K_{\beta 1}, K_{\beta 2}$, $K_{\beta 3}$, depending on the provenance subshells.

Indeed, in X-ray spectra from complex samples, the $M$ lines from high- $Z$ elements overlap the $K$ or $L$ lines of lighter elements so that a safe deconvolution of the multiplets must rely also on (experimental or theoretical) knowledge of the intensity ratios of the various $M$ lines.

Once an ionization has been produced in an inner shell, deexcitation of the atom can be accomplished by X-ray or Auger electron emission. The ratio of the number of X-ray emissions to the total number of ionizations produced in the given shell is called the fluorescence yield relative to that shell and is usually indicated with $\omega\left(\omega_{K}, \omega_{L}\right.$, etc.). For the $L$ and higher shells, subshell ionizations and consequently subshell fluorescence yields can be considered separately.

Fluorescence yields may be calculated theoretically and measured experimentally. They are a function of the atomic number $Z$, low for low- $Z$ elements and higher for high- $Z$ elements, higher for the $K \mathrm{X}$-rays with respect to the $L \mathrm{X}$-rays.

The product of ionization cross section and fluorescence yield for a given shell gives the cross section $\sigma_{X_{j}}$ for the production of an X-ray of the corresponding series (Fig. 2); from what has been said, it follows that $\sigma_{X_{j}}$ is also a function of $Z$ and $E_{\mathrm{p}}$. As stated above, within each series the branching ratio among the different lines is a slowly varying function of $Z$, and for the $L$ shell, this also depends a little on the particle bombarding energy. 

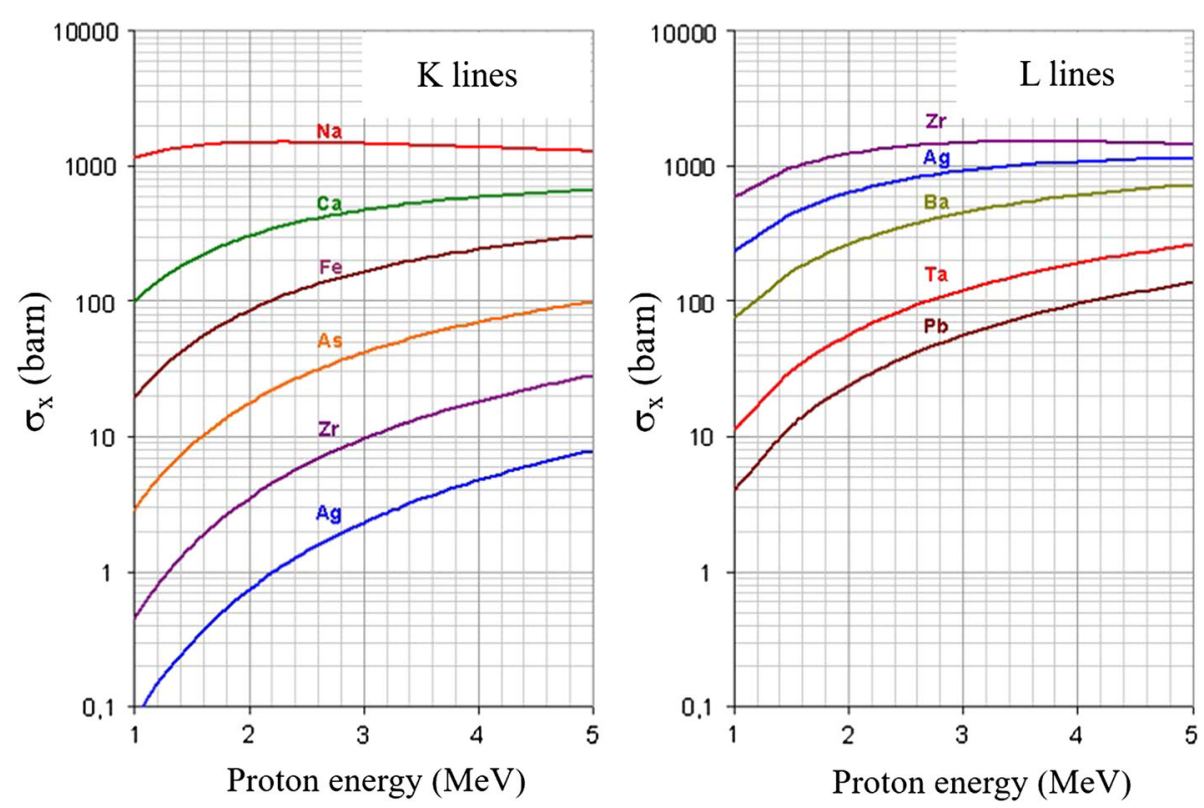

Fig. 2 Trends of cross sections as a function of the proton energy for different elements

An operational definition of 'thin' and 'thick' for a PIXE measurement can be given; for the moment, when referring to a thin specimen, let us think of a few atomic layers. Aerosol samples can be considered 'thin' samples; therefore, only the procedure for a quantitative PIXE analysis of thin samples will be presented.

In terms of X-rays produced, for a thin target, the equivalent of Eq. (1) is given by Eq. (2).

$$
N_{X_{j}}(Z)=\sigma_{X_{j}} N_{Z} t N_{\mathrm{p}}
$$

The angular distribution in the emission of the produced X-rays is isotropic with respect to the beam incidence.

Equation (2) can be rewritten in terms of areal density $\rho_{Z}$ t of the element $Z$ (mass per unit area normal to the beam, with $\rho_{\mathrm{Z}}$ standard volumic mass density) as:

$$
N_{X_{j}}(Z)=\sigma_{X_{j}} \frac{N_{\mathrm{Av}} \rho_{Z} \mathrm{t}}{A} \frac{Q}{e}
$$

where $N_{\mathrm{Av}}$ is Avogadro's number and $A$ the atomic mass of the species.

In Eq. (3), the number of protons $N_{\mathrm{p}}$ passing through the target is more conveniently expressed by integrated beam charge $Q$ divided by unit charge $e$. Indeed, $Q$ is usually an easily measurable quantity.

In a thin target, for any given element the X-ray production cross sections are constant throughout the target (because the beam energy loss is negligible, i.e., all interactions happen at the same proton energy, say $E_{0}$ ), and the number of detected X-rays is a well-defined fraction of those produced (isotropic emission of all X-rays). From Eq. (3), one obtains the number $Y_{0}$ of $\mathrm{X}$-rays from the element $Z$, detected during a measurement, simply by taking the overall detection efficiency into account. The latter is the product of a geometrical factor 


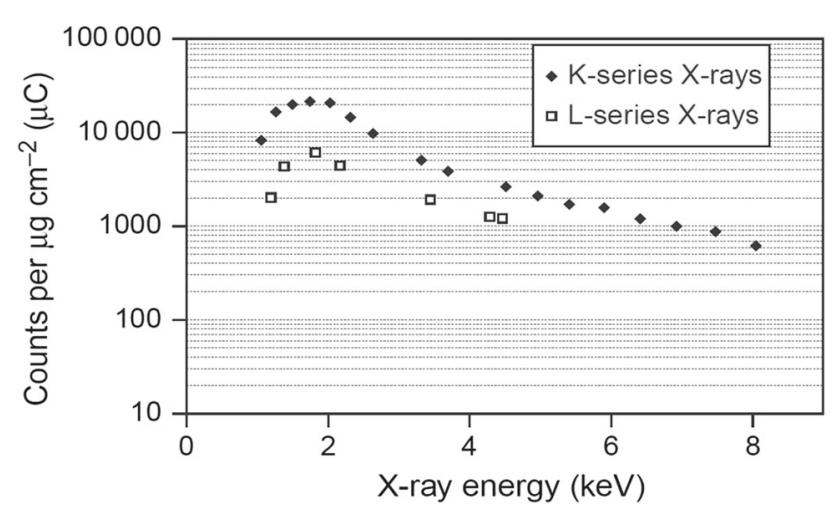

Fig. 3 Trend of efficiency factors versus X-ray energies, for $K$-series and $L$-series X-rays, with an $\operatorname{Si}(\mathrm{Li})$ detector covering a solid angle of $2.5 \mathrm{msr}(\sim 12.5 \mathrm{~mm} 2$ active area, $7 \mathrm{~cm}$ distance $)$. Experimental data obtained with thin standards by NIST certified to $\pm 5 \%$ accuracy

(related to the solid angle $\Omega$ covered by the detector) and of an intrinsic efficiency, $\varepsilon_{\text {det }}$, a function of the X-ray energy (and therefore of $Z$ ) depending on the detector characteristics.

$$
Y_{0 X_{j}}(Z)=\sigma_{X_{j}}\left(Z, E_{0}\right) \frac{\Omega}{4 \pi} \varepsilon_{\operatorname{det}} \frac{N_{\mathrm{Av}} \rho_{Z} t}{A} \frac{Q}{e}
$$

Equation (4) can be reorganized as follows

$$
Y_{0 X_{j}}(Z)=\eta Q \rho_{Z} t
$$

by defining an efficiency factor for the given X-ray, beam energy, detector and geometry (Eq. 6):

$$
\eta(Z)=\sigma_{X_{j}}\left(Z, E_{0}\right) \frac{\Omega}{4 \pi} \varepsilon_{\operatorname{det}} \frac{N_{\mathrm{Av}}}{A e}
$$

$\eta$ is obtained using a set of thin standards of known areal density by inverting Eq. (5).

Figure 3 show the curves for the efficiency factor as a function of X-ray energy (i.e., $Z$ ), for the $K$ and $L$ series, respectively, in a typical detector geometry.

In the case of aerosol samples, concentrations in $\mathrm{ng} \mathrm{cm}^{-2}$ are divided by the sampled air volume and multiplied by the deposited area to obtain the concentration in $\mathrm{ngm}^{-3}$.

\subsection{External beam setups}

An increasingly popular variant of conventional PIXE is external or 'in air' PIXE. This, as well as other IBA techniques, can be performed simply by passing the particle beam through a thin window, thus hitting the sample in its natural environment (Fig. 4). The beam size can be determined by an aperture in the last section of the beam path within the vacuum, whereas the X-ray detectors are external. The sample is placed a few millimeters from the window and, by using a positioning stage (with micrometric control), can be moved in the plane perpendicular to the beam for selective analysis. The external environment is often saturated with helium, to reduce beam energy loss and straggling with respect to air. The helium may be simply flooded in front of the exit window, with no containment, or be held in a simple closed environment. The use of helium has the further significant advantage that the transmission of low-energy X-rays is much higher than in air, which increases the possibility of detecting lighter elements. As an example, more than $96 \%$ of the $1.04-\mathrm{keV} \mathrm{K} \mathrm{X-rays} \mathrm{of}$ 


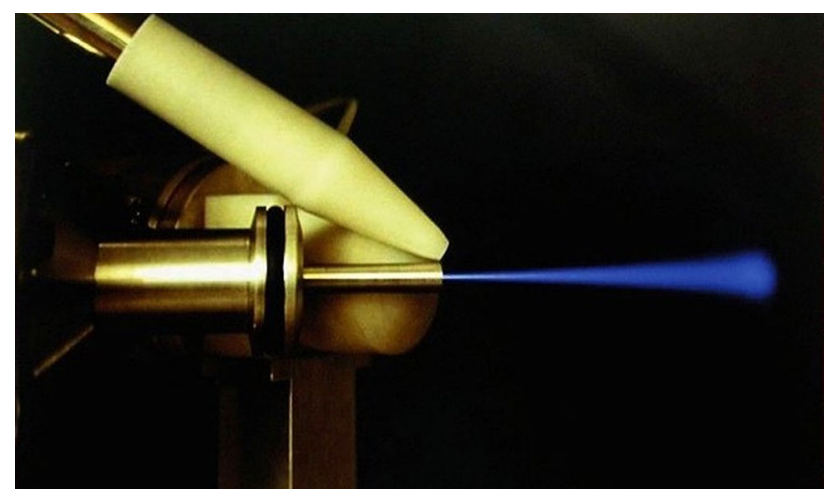

Fig. 4 External beam: note the florescence produced by the beam passing through the air. The straggling of the beam and the Bragg peak can be noted

sodium are still transmitted when traversing $3 \mathrm{~cm}$ of helium, whereas for a similar distance in air the transmission would be only $2.4 \times 10^{-6}$; for the X-rays of sulfur $(2.31 \mathrm{keV})$, the transmissions in $3 \mathrm{~cm}$ of helium and air are $99.7 \%$ and $28 \%$, respectively.

The main advantages of an external beam setup are the ease of handling and changing of the sample, the reduction in any possible risk of beam-induced damage to the sample, no electrical charging of insulated sample, ease of installation and change to the setup, no selective evaporation of volatile elements (like $\mathrm{Cl}$ or $\mathrm{Br}$ ). In external beam setups, the exit windows for the beam must be mechanically strong enough to sustain the pressure drop from the vacuum environment of the accelerator beam lines to atmosphere, and also exhibit a high resistance to radiation damage. Typical materials for beam exit windows are polymers like Kapton ${ }^{\circledR}$ or Upilex $\left(\mathrm{C}_{22} \mathrm{H}_{10} \mathrm{~N}_{2} \mathrm{O}_{4}\right)$, with $7.5 \mu \mathrm{m}$ thickness. The overall values for both the energy loss and straggling are therefore of little consequence to PIXE, due to the smooth trend of X-ray production cross sections with beam energy. Therefore, the possibility of a quantitative analysis is fully retained with external PIXE. Recently, ultrathin windows of $\mathrm{Si}_{3} \mathrm{~N}_{4}$, available down to a thickness of $0.1 \mu \mathrm{m}$, have been used due to their very high resistance to radiation damage [18].

As discussed in Sect. 2.3, the physics of X-ray production in PIXE unbalances the detection efficiency in favor of the low- and medium- $Z$ elements. This holds true even after using the favorable circumstance that $L$-series rather than $K$-series $X$-rays can be used for the quantification of higher- $Z$ elements. This unbalance is a problem when detection of low or trace quantities of high- $Z$ elements is required in the presence of a lower- $Z$ matrix. If the count rate due to the low-energy $X$-rays emitted by low- $Z$ elements is kept within tolerable limits, the total number of counts of $X$-rays from medium- and high- $Z$ elements is too small within reasonable measurement times. A possible solution is the use of two X-ray detectors simultaneously, which complement each other in terms of the efficiency curve and the solid angle covered. One detector is chosen to cover the widest possible solid angle (which increases efficiency regardless of the X-ray energy), but is prevented from obtaining a large count rate from low-energy X-rays by shielding its surface with an absorber of appropriate thickness. This reduces the efficiency for just the low-energy X-rays. This detector is thus optimized for the medium- and high- $Z$ elements, but, due to the absorber, it is blind to the lightest elements. The second detector, with no absorber but covering a much smaller solid angle, is then used to simultaneously provide analytical information concerning the low- $Z$ elements. 
The combined effect of the two-detector system, when both $L$ - and $K$-series lines are used, is that a much broader range of $Z$ is covered with more homogeneity in the detection efficiency.

A detailed description of the external beam setup at the LABEC laboratory is reported in Sect. 4.

\section{An overview on atmospheric aerosol}

Atmospheric aerosols (also referred as airborne particulate matter, PM) are defined as suspensions of any substance existing in the solid and/or liquid phase in the atmosphere (except pure water) under normal conditions and having a minimum stability in air assuring an atmospheric lifetime of at least $1 \mathrm{~h}$ [19]. Atmospheric aerosols show much differentiated concentration, composition, granulometric and morphological properties [20-22]. Primary aerosols are directly introduced into the atmosphere by natural or anthropic processes, such as the action of the wind, releases from volcanoes and exhaust emissions. On the contrary, secondary aerosols are generated by chemical and physical processes within the atmosphere, i.e., condensation of gases such as sulfur dioxide, nitrogen oxides and hydrocarbons. Particulate matter is removed by either dry deposition, i.e., settling due to gravity, or by wet deposition due to washout by raindrops. This atmospheric lifetime is short compared, for instance, with the lifetimes of gaseous constituents such as $\mathrm{CO}_{2}, \mathrm{CH}_{4}$ and CFCs (which is decades to centuries). For this reason, the aerosol content of the atmosphere is determined mainly by source neighborhood and atmospheric circulation, making the global and regional distribution of particulate matter highly variable in time and non-uniform in space [23]. Aerosols are transported by atmospheric motion over local, regional and planetary scales: Within the residence times cited above, particles may be found to travel as much as $\sim 5000 \mathrm{~km}$ from the source. The aerosols observed in the atmosphere are thus the result of the balance between different and competing processes: emission by sources, transport and deposition.

Particle sizes span several orders of magnitude, typically between $\sim 10^{-3}$ and $10^{2} \mu \mathrm{m}$. The size distribution of the particles is the result of the competition between aerosol sources and sinks. In a dry atmosphere, aerosols tend to form a tri-modal distribution, with a nucleation, an accumulation and a coarse mode. Coarse particles are mechanically produced by the breakup of larger bodies such as the soil, the sea and vegetation. They include, typically: wind-blown dust, sea spray, road dust re-suspended by traffic, pollen grains, etc. The amount of energy required to break up the particles increases as size decreases, and this sets a lower limit for the size of coarse particles, estimated in $\sim 1 \mu \mathrm{m}$. As these particles are large, dry deposition is their principal removal mechanism. Particles less than $0.1 \mu \mathrm{m}$ are generally formed by condensation of low-vapor-pressure substances formed at high temperatures or by chemical reaction: it is the nucleation process, also called gas-to-particle conversion. Particles in the nucleation mode grow rapidly by coagulation, i.e., the collision of two or more particles to form a larger particle, or by condensation of gaseous molecules on their surface. The efficiency of both processes is largest for smaller particles, and this circumstance produces an upper limit on diameter, of the order of 2-3 $\mu \mathrm{m}$ [24]. Particles smaller than a conventional threshold, usually $2.5 \mu \mathrm{m}$, are generally referred to as fine. Ultrafine particles or nanoparticles (diameter less than $0.1 \mu \mathrm{m}$ ) are efficiently dispersed by atmospheric motion. Neither settling nor diffusion is efficient sinks for the $0.1-1 \mu \mathrm{m}$ range, called the accumulation mode; their only efficient removal mechanism is wet deposition. Accumulation mode particles dominate radiative effects in the visible range, due to the fact that they are in a big number, and having a size comparable to wavelength, they have a large scattering efficiency. 
Aerosols are typically present in concentrations between a few $\mu \mathrm{g} \mathrm{m}^{-3}$ and $\sim 100 \mu \mathrm{g} \mathrm{m}^{-3}$, representing a tiny fraction of the atmosphere. Yet, atmospheric particles have important environmental effects: they modify the optical properties of the atmosphere, induce cloud and fog formation and thus affect the water cycle, and may cause a modification of the distribution of heat and thus of the circulation patterns, and they may affect the atmospheric chemistry and photochemistry by offering a surface for heterogeneous reactions. Moreover, aerosols may carry toxic metals, acids and nitrates, and thus may have a direct chemical effect at the act of deposition producing soil and water contamination, corrosion of materials, erosion of monuments and buildings, and damages to photosynthesis in vegetation.

Direct radiative forcing (through scattering and absorption) and indirect radiative forcing (through the interaction with the cloud formation mechanism) relate aerosols to the global issue of climate change. The scattering process determines a larger terrestrial albedo and thus a negative radiative forcing [25]; the absorption process, instead, is thought to cause heating of the earth and more specifically of the atmospheric layers where the aerosols reside, thus possibly influencing the modification of circulation patterns [26]. The indirect aerosol effect is due to the presence of cloud condensation nuclei $(\mathrm{CCN})$ which increase the number of cloud droplets and decrease their size for a given liquid water content, producing an increase in both cloud albedo and lifetime: these effects are thus thought to produce a negative radiative forcing.

The net effect of aerosols on climate is understandably difficult to quantify, but it seems that the overall effect is a negative radiative forcing, therefore opposite in sign to climate forcing due to increased concentration of greenhouse gases [27]. Consequently, aerosols are masking the real response of the climate system and that the temperature sensitivity of the earth is higher than observed [28].

Aerosols also have relevant effects on health: it is the breathing apparatus which is concerned, and the penetration depth of the particles therein depends upon particle size, nanoparticles $(<0.1 \mu \mathrm{m})$ being considered to be the potentially most dangerous. Particles larger than $\sim 10 \mu \mathrm{m}$, instead, are stopped in the uppermost respiratory system and quickly expunged. Particles smaller than $\sim 2.5 \mu \mathrm{m}$ enter the deep lung and are retained in the alveoli and their removal tends to happen via the blood stream [24]. Nanoparticles are retained in the lungs, where they hinder the exchange of oxygen and carbon dioxide with blood, and this independently of their chemical toxicity.

Since human health is adversely affected by exposure to air pollutants in air, the European Union has developed an extensive body of legislation, the Directive 2008/50/EC of the European Parliament and of the Council on ambient air quality and cleaner air for Europe, which establishes standard values for a number of pollutants present in the air. For instance, the limit for annual average allowed for $\mathrm{PM}_{2.5}$ (particles with a diameter smaller than $2.5 \mu \mathrm{m}$ ) is $25 \mu \mathrm{g} \mathrm{m}^{-3}$, and for $\mathrm{PM}_{10}$ (particles with a diameter smaller than $10 \mu \mathrm{m}$ ), it is $40 \mu \mathrm{g} \mathrm{m}^{-3}$ (with the limit of $50 \mu \mathrm{g} \mathrm{m}^{-3}$ per day, not to be exceeded for more than 35 days).

Aerosol sampling can be schematically described as follows. Air is pumped through a sampler, and particles are collected by impaction or filtration. In the impaction process, the air stream is forced to make an abrupt change in direction: heavier particles, due to inertia, cannot follow the air stream and impact onto an impaction foil. When filtration is used, instead, the air stream is forced through a filter substrate, where particles are retained. In the latter case, the lower limit of the sampled particle size range is a consequence of the properties of the filter substrate and particularly its porosity. An upper threshold on particle size may also be chosen with a pre-impaction stage, where large particles are retained. It has become a convention to use sampling heads admitting only particles with aerodynamic diameter $<10 \mu \mathrm{m}$, the $\mathrm{PM}_{10}$ fraction: this is motivated by the fact that this is the size range which is considered breathable. 
Since the importance of fine particles for their health and radiative impacts has been realized, the use of smaller thresholds has become common: besides $\mathrm{PM}_{10}$, most usually sampled fractions are $\mathrm{PM}_{2.5}$ and $\mathrm{PM}_{1}$, thought to be representative of fine particles. Fractionated or multi-mode samplers also exist, which separate the aerosol in several size ranges by arranging several stages in series.

Anthropogenic emissions in urban and industrialized areas can be large enough that the concentrations of various undesirable chemical species (pollutants) cause significant deterioration in air quality, affecting the visibility and posing threats to human health. For example, in December 1952, cold air moved from the English Channel and settled over London, producing a pollution trapping inversion fog. For 5 days, the smog was thick enough that people had to grope their way along the streets, buses crawled along at a walking pace led by pedestrians with flash lights, and indoor events were canceled because the stage could not be seen. By the time the smog had lifted, 4000 people had died of respiratory problems, and the smog was implicated in an additional 8000 deaths in the months that followed. Contrary to popular belief, particulate matter concentrations have declined (from 20 to $40 \%$ in the developed countries) in the past 20 years, thanks to the environmental policies adopted in many areas by the national or local governments. Anyway, there are still problems in many urban areas. In particular, nowadays, many large cities in developing countries (e.g., Beijing, Delhi, Jakarta), still suffer from London-type smog due to the burning of coal and wood and to the lack of strict air pollution controls on industrial emissions or traffic. Concentrations of PM in those megacities are very high, while the knowledge on its composition and its sources is still poor. For this reasons, the study of the aerosol composition in these environments is very important to understand health effects as well as to identify the main pollution sources and quantify their contribution, in order to develop appropriate mitigation measurements.

\section{PIXE setup for the analysis of aerosol samples}

To fully exploit the potential of PIXE in the analysis of the aerosol samples, the proper experimental setup is important. Since 1989 at the LABEC laboratory at Florence, an external beam line fully dedicated to the analysis of aerosol samples has been installed and developed and it has been widely used for the analysis of aerosol samples [29]. The use of an external beam for these measurements is really important. Apart from the ease of changing of the samples or the scanning of the filter, the possible loss of volatile elements is eliminated or reduced. The local heating due to the energy deposited by the beam is dissipated (even better in He atmosphere with respect to air); therefore, higher proton currents can be used. Furthermore, the solid angle covered by the detectors can be increased since they can be placed closer to the sample.

The extraction window originally used in our laboratory consisted of a $7.5-\mu \mathrm{m}$-thick Upilex-S foil. However, this polymer undergoes a progressive thinning/degradation during irradiation [30], and eventually, a finally rupture can happen. Therefore, we have substituted it with a Silicon Nitride $\left(\mathrm{Si}_{3} \mathrm{~N}_{4}\right)$ membrane, which is more durable under proton beam irradiation. We have chosen a 500-nm-thick, 3-mm-width membrane supplied by Silson Ltd. The aerosol samples are positioned at about $1 \mathrm{~cm}$ from the exit window. The charge flown during the measurement is measured by integrating the beam current on a graphite Faraday cup positioned just behind the samples. The aerosol deposit plus substrate are thin enough to let the beam pass through. 

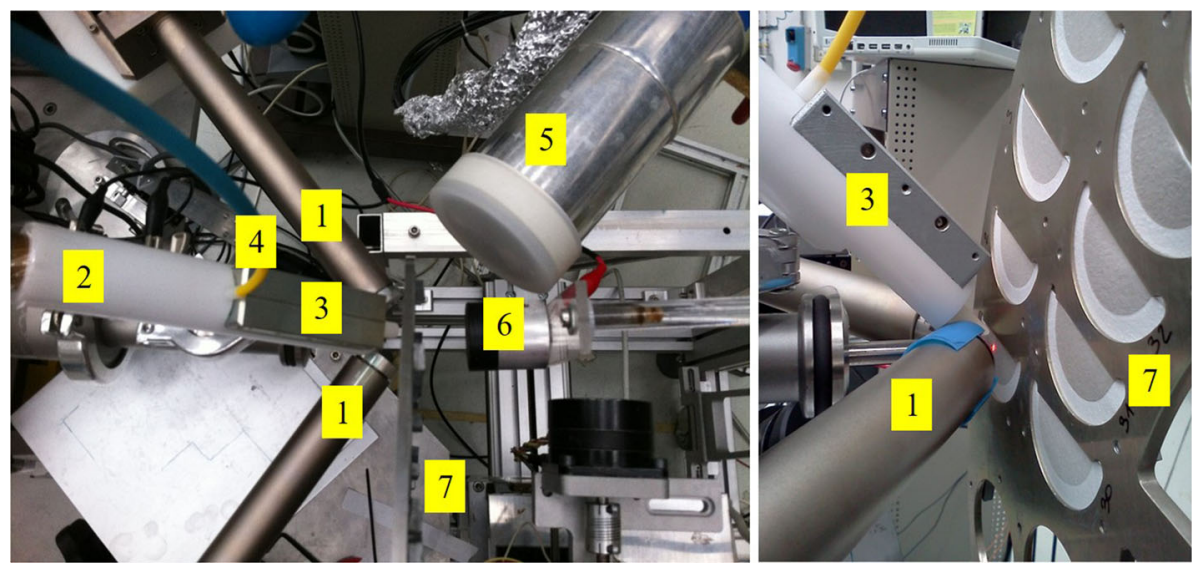

Fig. 5 Picture of the upgraded experimental setup: (1) new SDD for PIXE analysis of medium-high- $Z$ elements, (2) SDD for PIXE analysis of low- $Z$ element with proton deflector (3) and He flow (4), (5) Ge detector for PIGE, (6) Faraday cup for $Q$ measurement, (7) sample holder. On the right an expanded view where the sample holder for daily samples can be seen

The movement of the samples on the $x-y$ axes (to scan all the samples surface and to reduce the beam charge density on the sample) and the change of the samples by rotation of the sample holder are both remotely controlled by the acquisition system.

To obtain an efficient simultaneous detection of all the elements, two SDD detectors have substituted the previous $\mathrm{Si}(\mathrm{Li})$ detectors because they have a better resolution with modest cooling (down to $-40^{\circ}$ ) achievable with Peltier cells and can sustain higher counting rates (up to $50 \mathrm{kHz}$ at $0.5 \mu \mathrm{s}$ shaping time). Currents as high as more than $200 \mathrm{nA}$ can be used; with $\mathrm{Si}(\mathrm{Li})$ detectors at beam currents above 6-7 nA, the pileup reached unsustainable levels and saturation was reached in the preamplifier. Furthermore, the external case of the detector is smaller; therefore, the SDD detectors can be put closer the sample; as a consequence, lower measuring times can be used (typically $1 \mathrm{~min}$ or less compared to $5 \mathrm{~min}$ for a $\mathrm{Si}(\mathrm{Li})$ ) with better minimum detection limits (MDLs) [30].

We use a $40 \mathrm{~mm}^{2}, 450-\mu \mathrm{m}$-thick SDD, having $140 \mathrm{eV}$ FWHM energy resolution at the $5.9 \mathrm{keV} \mathrm{Mn} \alpha$ line and $1 \mu \mathrm{s}$ shaping time for the detection of the low-Z elements. It is placed at $145^{\circ}$ with respect to the beam direction, at $9 \mathrm{~cm}$ from the target; a magnetic proton deflector $(0.5 \mathrm{~T})$ was installed to prevent the damage of the detector by backscattered protons; it can deflect protons with an energy up to $4 \mathrm{MeV}$.

The medium-high- $Z$ elements are detected by two identical KETEK SDDs to double the statistics of the acquired spectra. Their characteristics are: $113 \mathrm{~mm}^{2}$ area (collimated to $80 \mathrm{~mm}^{2}$ ), $165 \mathrm{eV} \mathrm{FWHM} \mathrm{energy} \mathrm{resolution} \mathrm{at} \mathrm{the} 5.9 \mathrm{keV} \mathrm{Mn} \mathrm{K}_{\alpha}$ line and $1 \mu$ s shaping time, $450 \mu \mathrm{m}$ thickness. An absorber ( $450 \mu \mathrm{m}$ Mylar foil) is mounted to attenuate the low-energy X-rays. Both detectors are placed at about $2 \mathrm{~cm}$ from the target at $135^{\circ}$ with respect to the beam direction. The LABEC experimental setup is reported in Fig. 5.

It is important to choose the optimal measurement parameters depending on the type of samples we analyze (standard daily samples, samples with $1 \mathrm{~h}$ resolution, size segregated samples).

Aerosol sampling campaigns usually involve the collection of daily samples for a long period. Teflon $\left(\mathrm{CF}_{2}\right)_{\mathrm{n}}$ filters are frequently used because they have very good blank values and they are easily weighted. However, their content of fluorine gives rise to a strong Compton 
$\gamma$-ray background in the PIXE spectra, due to the high production rate of $\gamma$-rays, which worsens PIXE detection limits for medium-high- $Z$ elements. The measurements must be taken choosing a proton beam energy corresponding to minima in the proton-induced $\gamma$-ray emission cross section on fluorine [14]; therefore, we have chosen $3 \mathrm{MeV}$ on the target. The problems due to Compton background are drastically reduced because of the thinner thickness of the SDD and the shorter shaping time makes it possible to use higher currents. Each sample is irradiated with a proton beam intensity from 5 to $300 \mathrm{nA}$, depending on the loading of the filter for $45-60 \mathrm{~s}$. The MDLs are of the order of few $\mathrm{ng} / \mathrm{m}^{3}$ for the low $-\mathrm{Z}$ elements, down to a minimum value of $\sim 0.2 \mathrm{ng} / \mathrm{m}^{3}$ for $\mathrm{Cu}-\mathrm{Zn}$. A remote controlled multitarget holder is used for an automatic analysis of daily samples to exploit the intrinsic speed of the PIXE technique; it manages the change and the scan of 32 filters or 64 half filters. With this new setup, hundreds of samples can be analyzed in 1 day and this poses PIXE in an outstanding position for the elemental analysis of aerosol samples in campaigns where a high number of samples are collected. As reported in the introduction, it must be stressed that PIXE gives only a part of the information. For source apportionment studies, a complete characterization of the composition of the sample is necessary. Therefore, we use a protocol which combines multiple analytical techniques to obtain the mass closure (the complete reconstruction of the PM mass). Samples are collected by low volume $\left(2.3 \mathrm{~m}^{3} / \mathrm{h}\right)$ samplers (HYDRA Dual Sampler), equipped with two inlets to collect the aerosol simultaneously on Teflon and quartz fiber filters ( $47 \mathrm{~mm}$ diameter). One half of the Teflon filter is used to measure the concentrations of all the elements with atomic number $Z>10$ by PIXE. The water-soluble fraction of inorganic cations, inorganic anions and low molecular weight organic anions is measured by ion chromatography (IC) on one quarter of the filter [31]; ICP methods are used as a complementary technique with respect to PIXE, to determine the 'soluble fraction' of several major (ICP-AES) and trace (ICP-MS) metals on the remaining quarter of the filter [6]. A $1.5 \mathrm{~cm}^{2}$ punch of the quartz fiber filters is used for organic and elemental carbon assessment by thermo-optical transmission analysis [32] (using a Sunset Lab analyzer). Other analytical methods obtain, simultaneously with PIXE many elements, for example the water-soluble fraction of inorganic ions (e.g., $\mathrm{Na}, \mathrm{K}, \mathrm{Mg}, \mathrm{Ca}, \mathrm{Cl}$ ) measured by ion chromatography, or $\mathrm{Al}$, $\mathrm{Ti}, \mathrm{V}, \mathrm{Cr}, \mathrm{Mn}, \mathrm{Fe}, \mathrm{Ni}, \mathrm{Cu}, \mathrm{Zn}, \mathrm{As}, \mathrm{Se}, \mathrm{Sr}, \mathrm{Zr}, \mathrm{Pb}, \mathrm{Ba}$ measured by ICP-MS or ICP-AES. This allows a quality assurance control on the huge quantity of data obtained in many campaigns which otherwise would not be possible.

With the same setup, we can also analyze samples collected by the so-called streaker sampler [10]. This device collects the fine and coarse fractions of the aerosol on two stages, which are paired on a cartridge rotating at constant speed. This produces, on both stages, a circular continuous deposit of particulate matter ('streak'), which can be analyzed 'point by point' by PIXE. The scan of the whole streak, corresponding to 1 week with 1 h resolution, means the analysis of $168 \times 2$ spots considering that we measure both the fine and the coarse fraction. With currents in the range 100-300 nA (this would not be possible in vacuum, with no heat dissipation, or with $\mathrm{Si}(\mathrm{Li})$ detectors), measuring times down to about $30 \mathrm{~s}$ may be used for most of the samples, but longer times (e.g., $1 \mathrm{~min}$ ) are used to achieve better detection limits. Nowadays the measurement of a streaker foil takes less than $3 \mathrm{~h}$, with still better detection limits than the ones that were obtained when using a measuring time of more than $10 \mathrm{~h}$ with the $\mathrm{Si}(\mathrm{Li})$ detectors. The reduction in the measuring time, together with the high request of compositional data with hourly resolution for aerosol research studies, has led to a constant increase in the application of PIXE on streaker samples at LABEC. To find the optimal beam energy with this kind of samples, we performed a systematic study of the minimum detection limits (MDLs) as a function of the energy of the proton beam. The increase in the proton beam energy produces the increase in the X-ray production cross 
sections, but also an increase in the background. Therefore, proton beam energies between 2.5 and $3.0 \mathrm{MeV}$ are the best compromise to measure all the detectable elements in aerosol samples.

\section{Examples of applications of PIXE to aerosol studies}

We report some examples of the application of PIXE technique at LABEC to show the potentialities of PIXE for aerosol studies.

\subsection{Urban pollution (source apportionment)}

The study of aerosol composition for the identification of aerosol sources and the quantification of their contribution to PM mass (source apportionment) is a prerequisite to develop science-based effective policies for the aerosol pollution abatement. Receptor models (RM) apportion the measured PM mass to its emission sources from environmental concentrations of pollutants (and their uncertainties) measured at the receptor site. Positive matrix factorization is nowadays the most widely used RM [33].

PIXE analysis of aerosol samples allows simultaneous detection of many elements, including important tracers of many particulate matter sources. This capability, together with the possibility of analyzing a high number of samples in very short times, makes PIXE a very effective tool for source apportionment studies by receptor modeling. However, some important tracer, like levoglucosan (related specifically to biomass burning), and other aerosol components, like organic carbon (OC), elemental carbon (EC) and nitrates, must be measured by complementary nonnuclear techniques.

An example of source apportionment study in which PIXE played an important role is the European Life + AIRUSE project (www.airuse.eu). The AIRUSE project produced the first harmonized data set for southern European cities of $\mathrm{PM}_{10}$ and $\mathrm{PM}_{2.5}$ levels and composition, following the same sampling and analytical protocol in Barcelona (Spain), Porto (Portugal), Athens (Greece), Florence and Milan (Italy). We have used PIXE data together with those obtained by other analytical techniques (following the approach reported in $\$ 4$ ) to reconstruct the average aerosol chemical composition and PMF analysis to determine the aerosol sources and their impact on $\mathrm{PM}_{10}$ and $\mathrm{PM}_{2.5}$ mass. Previously, the comparison of data obtained by both PIXE and other different techniques (e.g., ion chromatography, ICP-MS/AES) allowed the quality assurance control on the huge quantity of data obtained in the project. An example of the results regarding the source apportionment is reported in Fig. 6 for Florence. After the identification of the main aerosol sources, the strategic goal of the AIRUSE project was to test and develop specific measures to improve air quality in southern Europe, targeted to meet air quality standards and to approach as closely as possible the WHO guidelines. Detailed results are reported in [34-36].

Some interesting results are: (1) We have identified a separated contribution of vehicle non-exhaust (due, e.g., to the re-suspension of soil dust by vehicles, brake- and tire wear) and vehicle exhaust thanks to the measurement of all the soil-related elements by PIXE. For $\mathrm{PM}_{10}$, in all the cities traffic gives the most important contribution, but it is worth noting that the contribution of the two subcomponents is comparable. (2) Biomass burning, which is considered 'green energy,' emits many toxic elements (like As and $\mathrm{Pb}$ ) and it gives an important contribution to PM mass even more relevant in the most polluted days, except for Barcelona. This difference is mostly due to the degree of penetration of wood (and its derivatives) as fuel for residential heating. In Barcelona, natural gas is very well supplied 

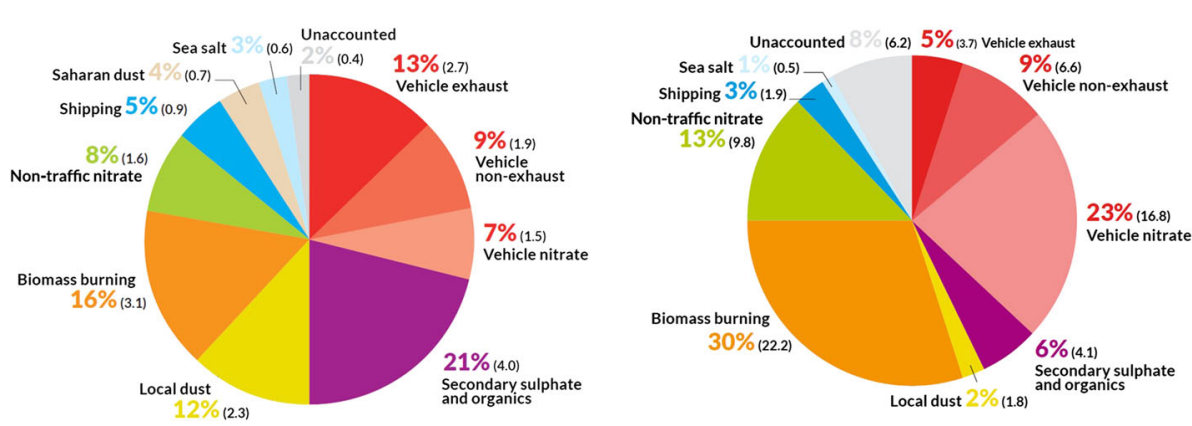

Fig. 6 Simplified source apportionment in the AIRUSE city of Florence. Contributions $\left(\%\right.$ and $\left.\mu \mathrm{g} / \mathrm{m}^{3}\right)$ to the annual mean for PM10 (left) and during days with PM10>50 $\mu \mathrm{g} / \mathrm{m}^{3}$ PM10 (right)

across the city and used as fuel in $96 \%$ of homes. (3) Thanks to the good quality of PIXE data, in some cities (e.g., Florence) it was possible to separate the contribution of the Saharan dust from that of the local dust (due to anthropic activities like construction/demolition works).

\subsection{Determination of the elemental concentrations with $1 \mathrm{~h}$ resolution}

The importance of the measurement of the aerosol composition with high time resolution is described in the introduction. With the typical samplers like the steaker one, described in $\S$ 4 , the overall quantity of aerosol deposited on each section is minute, typically of the order of $10 \mu \mathrm{g}$. The high absolute sensitivity of PIXE is therefore exploited to the highest degree. No other technique enables the analyst to obtain such a high time resolution of the variation in aerosol composition, with simultaneous sensitive detection of a very large number of elements in runs lasting a few minutes.

PMF analysis of hourly data reinforces the source identification obtained by daily samples, since the impact of many sources like industries, biomass burning or vehicular traffic is more evident on an hourly time basis. Furthermore, it is possible a more direct correlation with wind direction and speed, since on a daily scale the wind direction may have strong variations. Source polar plots, which show the wind direction and intensity dependence of the resolved factors, can be therefore easily produced from PMF streaker results. They help to find the location of the identified sources. For example, in AIRUSE [34] the time trend of the biomass burning source supports the identification of it as biomass burning for domestic heating (Fig. 7-up) because of its periodic pattern with peaks starting in the evening and lasting several hours. The absence of the evening night peak on some days is explained by the meteorological conditions. Some peaks during the day are connected to open fires due to the pruning. The source polar plot shows that in the case of Florence it is a local source (Fig. 7-down), but a contribution coming from the hills on the northeast sector is evidenced. Other examples of application regard Madrid [37], Barcelona [38], London [39] or Japan coastal areas [40].

Elemental concentration obtained with $1 \mathrm{~h}$ resolution can give invaluable information for the study of episodic events, lasting a few hours which may lead to an exposure problem like the ones occurring in industrial sites. An example regards the identification and apportionment of emission sources of particulate matter pollution in the vicinity of the integrated steelwork complex located in Port Talbot, UK [41]. For many years, air quality in the town was one of the worst in the UK. The steelwork units are coke making, sintering, blast furnace, basic oxygen furnace and other steel processing units. The aim was to identify the steel emission 
(a)

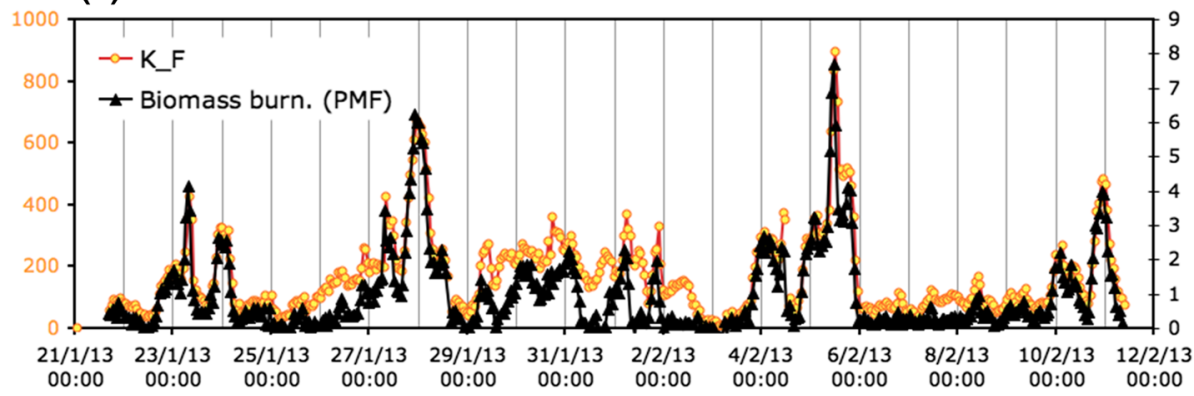

(b)

Fine Biomass Burning

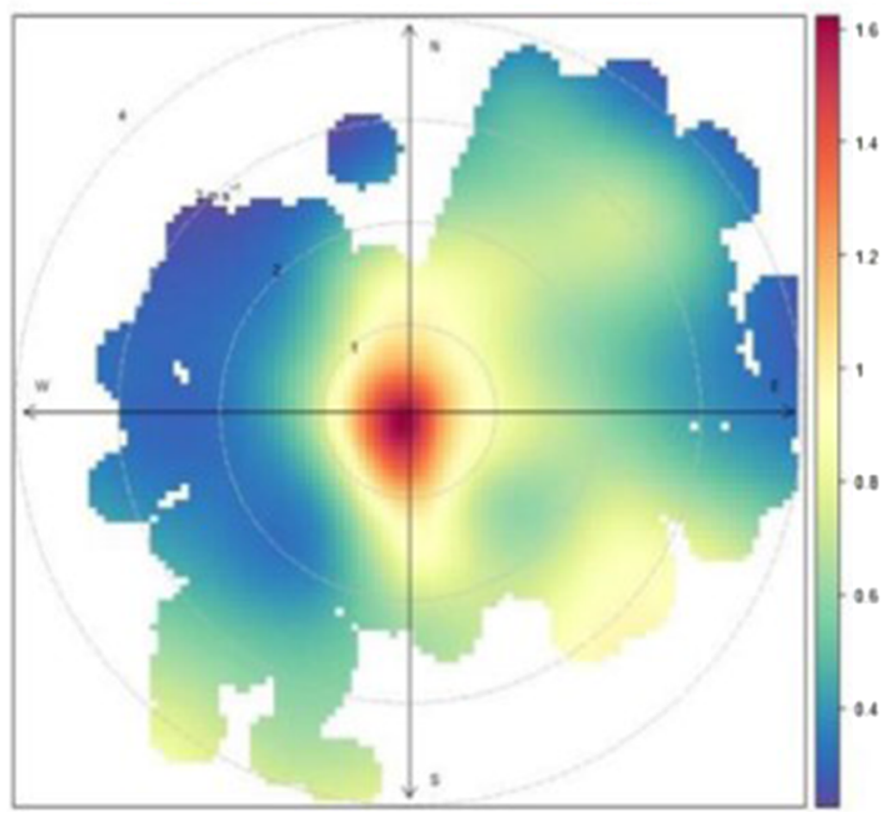

Fig. 7 Up: Temporal patterns of the biomass burning (BB) source in the fine fraction (in arbitrary units) together with $\mathrm{K}$ concentration (typical marker of $\mathrm{BB}$ ) in $\mathrm{ng} / \mathrm{m}^{3}$ in Florence. Down: Source polar plot as a function of wind direction and speed in the fine fraction. The direction is the wind direction, the distance from the origin is the wind speed, and the color is the source strength (blue: low, red: high)

profiles and to attribute emissions to specific production units in the integrated steel complex. The hourly data collected at Port Talbot captured the peculiarities of different emissions and were effective in resolving contributions from different steelwork units that the daily data could not always detect due to the short time characterizing these emissions. Moreover, the hourly resolution demonstrated high metal concentrations lasting a few hours which may lead to an exposure problem in this area.

A similar investigation was performed also at Taranto, Italy, where an extended industrial pole in the northern suburbs of the town includes one of the biggest Italian refinery, a power plant, a big cement industry and the biggest steel plant of Europe. These activities, developed very close to residential areas, heavily stress the environment of the town. The aerosol was 

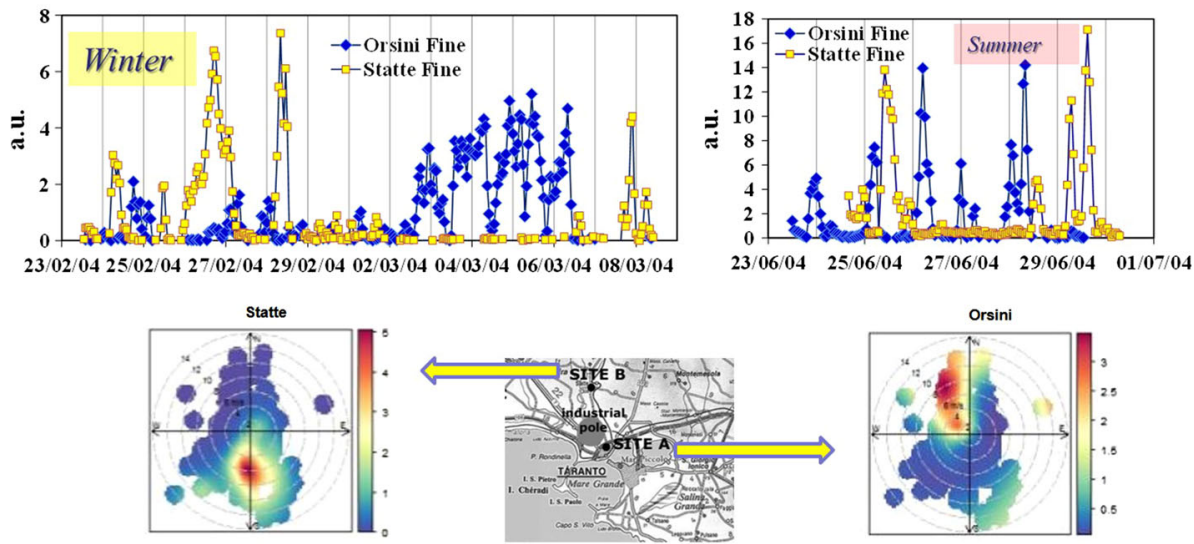

Fig. 8 Upper part: Temporal patterns of the identified factors in the fine fraction (in arbitrary units) in both sampling sites. Lower: Taranto map (center), showing the location of the industrial area and of the sampling sites, and source polar plots for the two sites

collected by two streaker samplers in parallel in two different sites: an urban district in Taranto adjacent to the industrial area and a small town located $7 \mathrm{~km} \mathrm{N-NW}$ of Taranto located along the direction of prevalent winds from the industrial area. The location of the sampling sites allowed us to follow the impact of the industrial plume as a function of wind direction. The hourly data collected at the two sites in Taranto area captured the peculiarities of different emissions from the integrated steelmaking facility and were effective in resolving contributions from different steelwork units. The location of the sampling sites, in opposite position with respect to the industrial site, allowed us to follow the impact of the industrial plume as a function of wind direction (Fig. 8). Again, the hourly resolution demonstrated high metal concentrations lasting a few hours which may lead to an exposure problem in this area. The presence of other anthropogenic and natural sources was also identified.

Pyrotechnic events, such as New Year's Eve, national festivities and light festivals, give rise to large but transitory (up to hours) increases in urban atmospheric particulate matter mean levels (up to hundreds of $\mu \mathrm{g} / \mathrm{m}^{3}$ ), especially metalliferous particles ( $\mathrm{K}, \mathrm{Mg}, \mathrm{Ba}, \mathrm{Cu}, \mathrm{Sr}$, $\mathrm{Al}, \mathrm{Pb}$ ) which can be dangerous for the human health. In [42], the aerosols generated by highintensity pyrotechnic events, called mascletàs, are studied. These events take place during annual festivals in numerous cities in the Spanish Valencian Region. Unlike usual fireworks, mascletàs are used to stimulate the auditory system and body vibration through the strong rhythmic noise sequence produced by the burning of a type of bangers called masclets. The masclet is a powerful sound firecracker that can be burst both at ground level and at low altitude level (1.5-2.0 m). When it burns, a loud intensity detonation, light effects and abundant smoke generation are produced as a function of its composition. During mascletàs, hundreds of firework shells are also shot into the air using vertical cannons. People attending these events are directly enveloped by the aerosol clouds which are produced. In [42], the emission aerosol cloud is measured directly since the sampling point was located very close to the launching zone. We found extremely high concentrations in the fine fraction, with maximum values above $500 \mu \mathrm{g} / \mathrm{m}^{3}$ for $\mathrm{K}, 100 \mu \mathrm{g} / \mathrm{m}^{3}$ for $\mathrm{S}$ and $300 \mu \mathrm{g} / \mathrm{m}^{3}$ for $\mathrm{Cl}$, with increase factors of more than 1500 with respect to the background levels (Fig. 9). Elements related to pyrotechnic displays like $\mathrm{Al}, \mathrm{Mg}, \mathrm{Cu}, \mathrm{Co}, \mathrm{Zn}$, and $\mathrm{Pb}$ also presented a large rise, with increase factors above 100 , mainly in the fine fraction in comparison with their normal 

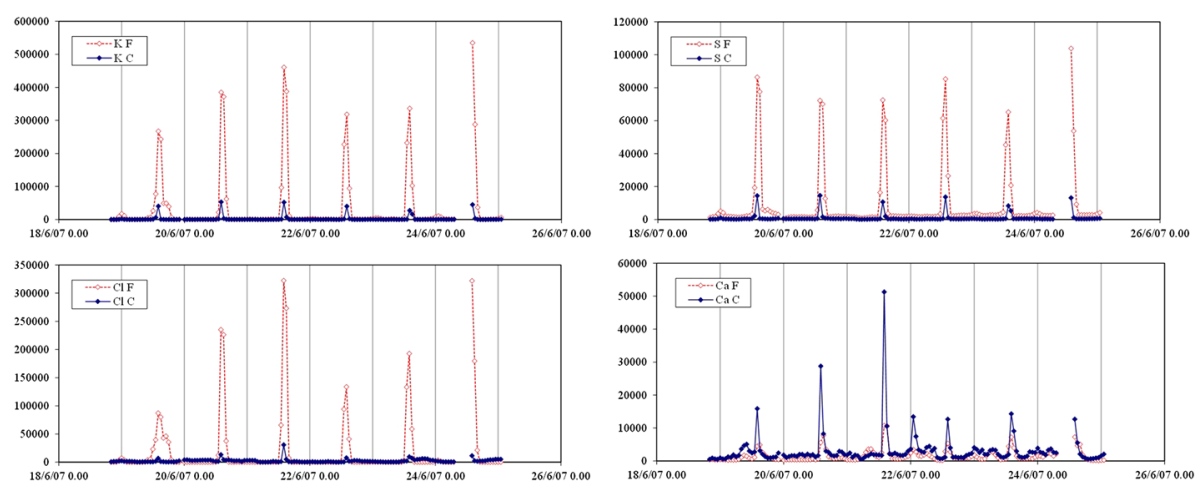

Fig. 9 Temporal patterns of the $\mathrm{K}, \mathrm{S}, \mathrm{Cl}$ and $\mathrm{Ca}$ (concentrations in $\mathrm{ng} / \mathrm{m}^{3}$ ) in the fine and coarse fraction during the sampling period at Alicante (Spain)

values. In the case of $\mathrm{Sr}$ and $\mathrm{Ba}$, factors up to $\sim 1000$ were observed. The concentrations found in the mascletà plumes were not constant due to variability of gunpowder composition and pyrotechnic devices used to attain specific firework effects. Some of the identified metals are dangerous elements because of their toxicity, like $\mathrm{As}$ and $\mathrm{Pb}$ (with concentrations up to 0.17 and $5 \mu \mathrm{g} / \mathrm{m}^{3}$, respectively). Such very high concentrations in a short time in a place where thousands of people are gathered may be of concern, particularly for people who suffer from chronic respiratory health problems, cardiovascular disease, etc.; furthermore, $\mathrm{Cl}$ in such high concentration is dangerous for the environment.

\subsection{Natural aerosol}

The interest in the study of natural aerosol is justified by the fact that Saharan dust is a major component of PM on a global scale and its atmospheric concentrations have relevant effects on climate, due to the influence on the earth atmosphere radiative budge, and environment; in southern Europe, it gives an important contribution to PM and it can episodically increase significantly the $\mathrm{PM}_{10}$ levels above the limit of $50 \mu \mathrm{g} / \mathrm{m}^{3}$. The EU Air Quality Directives specify that $\mathrm{PM}_{10}$ limit values have not to be applied to events defined as natural, which include 'long-range transport from arid zones.' Diffusion models and satellite images observation can be very effective in the study of Saharan dust transport; however, the advection of air masses coming from Sahara does not necessarily imply high $\mathrm{PM}_{10}$ concentrations at ground level. Therefore, only field campaigns, followed by elemental analysis, can assess the real impact of the Saharan dust episodes on the air quality, so deserving a key role to the PIXE technique. An estimate of the soil dust component concentration can be calculated from the measured elemental concentrations as the sum of all the main crustal element oxides $\left(\mathrm{Na}_{2} \mathrm{O}, \mathrm{MgO}, \mathrm{SiO}_{2}, \mathrm{Al}_{2} \mathrm{O}_{3}, \mathrm{TiO}_{2}, \mathrm{~K}_{2} \mathrm{O}, \mathrm{CaO}, \mathrm{Fe}_{2} \mathrm{O}_{3}\right)$.

$$
\begin{aligned}
{[\text { soil dust }]=} & 1.35[\mathrm{Na}]+1.66[\mathrm{Mg}]+1.89[\mathrm{Al}]+2.14[\mathrm{Si}] \\
& +1.21[\mathrm{~K}]+1.40[\mathrm{Ca}]+1.67[\mathrm{Ti}]+1.43[\mathrm{Fe}]
\end{aligned}
$$

Finally, natural dust contains $\mathrm{Fe}$, an important nutrient in marine ecosystems; the deposition of dust iron to the ocean affects the $\mathrm{CO}_{2}$-carbon cycle and this in turn can affect climate.

EMEP (European Monitoring and Evaluation Programme) is a science-based and policydriven program under the Convention on Long-range Transboundary Air Pollution for inter- 
national cooperation to solve transboundary air pollution problems. The measurement of mineral dust is not generally included as a routine part of the monitoring programs even though it is a compulsory part of the EMEP monitoring program and chemical speciation is recommended by the World Meteorological Organization (WMO) Global Atmospheric Watch (GAW), probably due to the lack of a reference method. EMEP periodically organizes intensive monitoring campaigns; in 2012-2013, one of the major focuses was to measure chemical speciation in $\mathrm{PM}_{10}$ with a special emphasis on mineral dust, with samplings on a daily base for two one-month periods in 20 regional background sites representing different European rural background environments, by using an identical approach with respect to both sampling and subsequent speciation analysis of the mineral dust content. The aim was to produce a unique data set which enables an extensive evaluation of sources, transport and regional distribution of mineral dust across the European continent. The Chemical coordinating Centre decided to assign to LABEC the measurement of all the filters ( 1000 Teflon filters were analyzed) collected in the two intensive campaigns for the determination of all the soil-related elements because of the good accuracy and speed of PIXE analysis. Detailed results are reported in [43].

Dust may also greatly increase locally the atmospheric levels of PM, adversely affecting air quality. This effect is especially relevant in southern Europe due to the transport processes from Africa and the Arabian Peninsula and to the relatively low precipitation, which causes a long residence time of PM in the Mediterranean atmosphere. These episodes may cause exceedances of the $\mathrm{PM}_{10}$ daily limit value of $50 \mu \mathrm{g} / \mathrm{m}^{3}$; therefore, many recent studies have focused on the estimation of the influence of African dust on air quality especially in southern European countries. As the impact of desert dust at ground level is well characterized by an increase in all soil-related elements and changes in elemental ratios, field campaigns followed by elemental analysis can be very effective to assess the real impact of these episodes on PM at ground level. PIXE can play a leading role since it is a rapid analytical method that allows the assessment of the concentration of all soil-related elements on many samples in a short measuring time. To distinguish between local soil dust and Saharan dust, a stringent signature may be given by elemental ratios [12]. Examples of this approach are reported in $[11,44,45]$.

As a final example, we report some results taken from the first study of the elemental composition of dust exported to the North Atlantic at Izaña Observatory (Tenerife) with high time resolution $(1 \mathrm{~h})$. The aim was to answer to three questions: How quick does dust composition change in the Saharan Air Layer (SAL)? What is the connection to dust sources? What is the role of meteorology? In Fig. 10, the ratio $\mathrm{Ca} / \mathrm{Al}$ is reported. A change of a factor up to 2 can be noted in only $6 \mathrm{~h}$. Along 1 week of continuous dust presence at Izaña $\left(50-200 \mu \mathrm{g} / \mathrm{m}^{3}\right), 7$ concatenated impacts, which were traced by the variability in the ratios of the different elements to $\mathrm{Al}$, were observed. This variability was induced by the alternated impacts of three of the large North African dust sources (NE Algeria, Western Sahara to Bechar region and SW Sahara-Western Sahel). The potential source areas of dust were identified by analyzing the 'median ratios at receptor' (MRAR) plots (Fig. 11), the median ratio of each element $\mathrm{X}$ to $\mathrm{Al}$, measured at the receptor site (Izaña) when the air mass was previously passed above each $1^{\circ} \times 1^{\circ}$ degree pixel over North Africa. Back-trajectories were calculated with HYSPLIT software [46].

We found a correlation between dust composition in the SAL and NAFDI (North African Dipole Intensity), the ratio of the tropical Saharan high-Morocco- to the monsoon tropical low-Nigeria that is the difference of the anomalies of the daily values of the $700 \mathrm{hPa}$ geopotential height $\left(\Phi_{(\mathrm{d})}\right)$ over Morocco $\left(\mathrm{Mo}, 30-32^{\circ} \mathrm{N}, 5-8^{\circ} \mathrm{W}\right)$ and Nigeria $\left(\mathrm{Ni}, 30-32^{\circ}\right.$ $\mathrm{N}, 5-8^{\circ} \mathrm{E}$ ), with respect to the climatological (average) values from 1980 to $2010\left(\Phi_{(\mathrm{clim})}\right)$ 


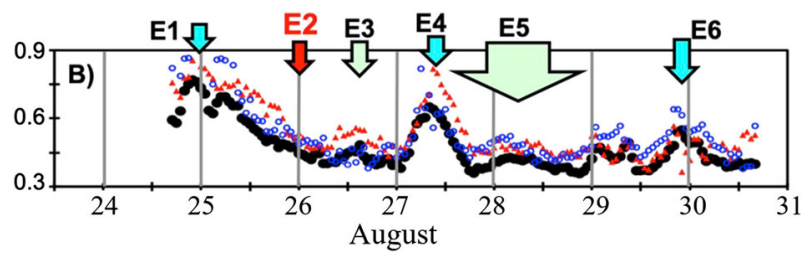

Fig. 10 Time series of the ratio of the hourly concentrations of $\mathrm{Ca}$ to $\mathrm{Al}$ in total, coarse $(2.5-10 \mu \mathrm{m})$ and fine $(<2.5 \mu \mathrm{m})$ dust fractions at Izaña Observatory from 23 August $19 \mathrm{~h}$ to 30 August $17 \mathrm{~h} 2010$. Ratios are shown in the period when Izaña was impacted by the Saharan Air Layer
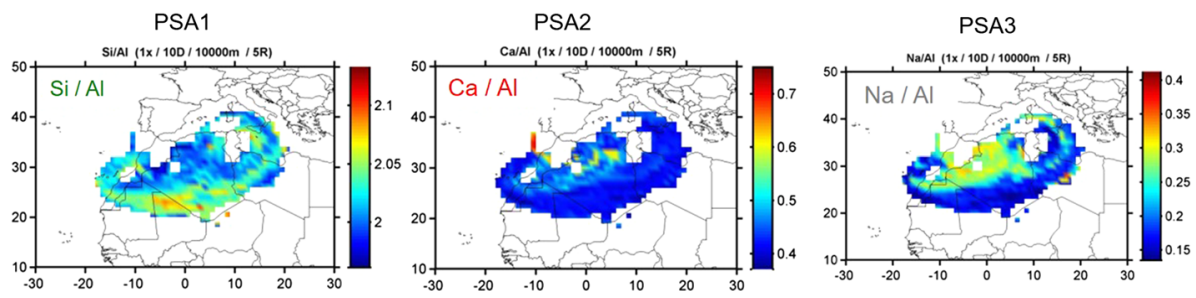

Fig. 11 Median ratios at receptor-MRAR - plots. Ratios of $\mathrm{Si}, \mathrm{Ca}$, Na, to $\mathrm{Al}$ measured in the dusty SAL at Izana (24 Aug $17 \mathrm{~h}$ to $30 \mathrm{Aug} 16 \mathrm{~h}$ ), based on 144 back trajectories

$$
\mathrm{NAFDI}=\frac{1}{10}\left(\left(\Phi_{(d)}-\Phi_{(\operatorname{clim})}\right)_{\mathrm{Mo}}-\left(\Phi_{(d)}-\Phi_{(\operatorname{clim})}\right)_{\mathrm{Ni}}\right)
$$

NAFDI traces the variability of summer meteorology. Positive phase of NAFDI enhances dust export to the North Atlantic. Negative phase of NAFDI enhances dust export to the Western Mediterranean. The NAFDI traces the observed variability in dust composition. NAFDI values $(0$ to +2$)$ were associated with $\mathrm{Ca}-, \mathrm{K}-, \mathrm{Na}-, \mathrm{Mg}$ - and $\mathrm{S}$-rich dust linked to dust sources in NE Algeria, whereas higher NAFDI values (2 to 4) were linked to Fe-rich dust (Ca-, Na- and S-depleted) linked to dust sources in SW Sahara-Western Sahel.

These results show that long-term variability of meteorology in North Africa may have implications on the composition of the dust exported to the North Atlantic and this is relevant for the interconnection between aerosol desert dust, meteorology and climate. Detailed results are reported in [47].

\subsection{Paleoclimatic studies}

Insoluble mineral aerosol deflated from continental surfaces is an important player in earth's climate by its influence on the earth atmosphere radiative budget. To reconstruct the past atmospheric concentration of mineral dust and to correlate its variations with climatic changes, dust stratigraphies have been obtained by the chemical and physical analyses on ice cores drilled in polar areas. For the Southern Hemisphere, ice core drilled in Antarctica can give relevant information on the hydrological cycles of the southern South America (the most relevant dust area for Antarctica during glacial periods) and on the different transport processes of air masses from medium latitude, as a function of the changes in the climatic belts. The geochemical and isotopic composition of Antarctic dust both in the ice cores and in the present-day aerosol is used to infer dust source locations and to study the geochemical evolution, linked to paleoenvironmental conditions of dust at the source. These analyses 

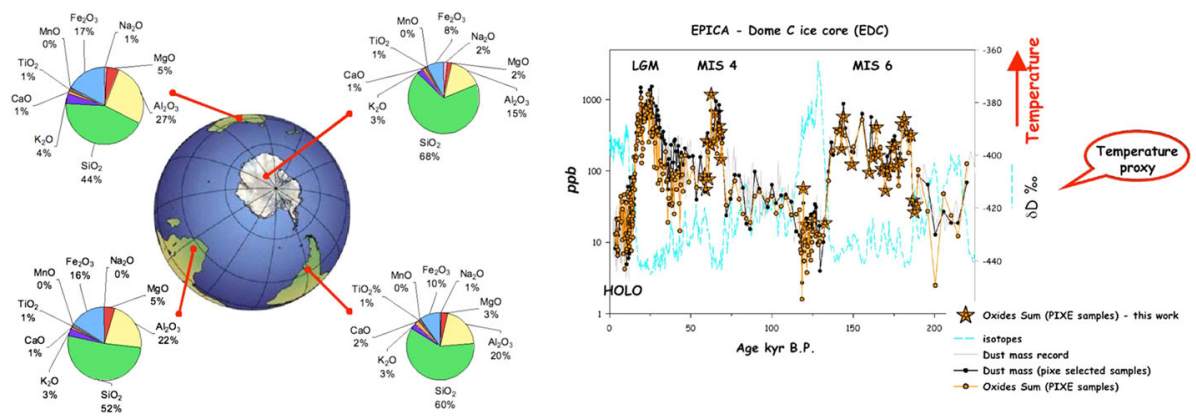

Fig. 12 Left: Geochemical characterization of ice dust and PSA sediments. Ice dust composition during the cold stages (MIS4 and MIS6). Right: Dust mass concentration in the ice core from Dome C. $\delta \mathrm{D}$ is the deuterium/hydrogen ratio in ice and it is widely used as a temperature proxy [49]

are particularly challenging because of the extremely low elemental concentrations usually present in the insoluble particulate in Antarctic ice cores (pg to $\mu \mathrm{g}$ per $\mathrm{kg}$ of ice). PIXE technique has proved to be a reliable tool for major and minor elements investigation. Ice core sections are melted and the liquid is filtered through a small area membrane to concentrate the insoluble dust to obtain detectable concentrations. No other sample pre-treatment is necessary; therefore, any possible contamination is minimized compared to ICP-MS. The quantity of dust collected $\left(\sim 1-2 \mu \mathrm{g} / \mathrm{cm}^{2}\right.$ in the scarcest samples) in ice core samples is sufficient to obtain good statistics [48].

In the framework of the EPICA (European Project for Ice Coring in Antarctica) project, an ice core was drilled at Dome C in the East Antarctic Plateau [49]. Some ice dust samples from the ice core were analyzed. Such an ice core spans the last $800 \mathrm{kyr}$; the measured samples regard the main cold events of the last $220 \mathrm{kyr}$, except the last one (i.e., they cover the cold periods called MIS4 and MIS6, the two glacial stages before the last one, called Last Glacial Maximum, LGM).

Soil sediment samples collected in the main 'potential source areas' (PSAs) for Antarctica, i.e., southern South America, Australia and South Africa, were also analyzed to compare their elemental composition with the ice core dust one. For a reliable comparison, soil particle size selection has been done on PSA samples, because long-range transport produces a strong dimensional selection of the dust particles in the atmosphere. (Antarctic dust is only composed of fine particles with diameter $<5 \mu \mathrm{m}$.) After the proper preparation, all the samples are analyzed by PIXE and PIGE, since the absolute quantity of the lighter elements (such as $\mathrm{Na}, \mathrm{Mg}, \mathrm{Al}$ and $\mathrm{Si}$ ) can be somewhat underestimated because of the X-ray self-absorption inside each individual aerosol particle [48].

Coming to the main results, the measured compositions of ice dust and PSA sediments are reported in Fig. 12, left. As mineral dust is only composed of the oxides of the detected elements, the measured compositions are expressed as the percentage of every oxide with respect to the total mass. From this geochemical characterization, ice dust composition during the cold stages (MIS4 and MIS6) seems to be quite similar to the South American one, while it relevantly differs from both the Australian and the South African one. For the measured ice samples, the oxide sums calculated from the measured elemental compositions agree very well with the dust mass measured with other techniques (Fig. 12, right). There is an evidence that dust concentrations are much higher during the cold periods (LGM, MIS4 and MIS6), than during the hot periods. 


\section{Conclusions}

PIXE is still a useful technique for the analysis of aerosols. However, a proper experimental setup and the proper experimental conditions must be used to fully exploit PIXE capabilities.

PIXE is unrivaled for the study of natural aerosols such as mineral dust or marine aerosols. The simultaneous detection of several important source tracers is fundamental for the application of receptor models such as PMF. The measuring times for the analysis of standard daily samples are far shorter than those typical of XRF systems and shorter with respect to the ICP methods (PIXE does not need any sample treatment); therefore, it is possible to analyze many samples in short times. Another field in which PIXE has a main role is the study of high-time-resolution samples, which is very useful for the identification of the aerosol sources, to understand physical-chemical processes and to assess real human exposure. Finally, the PIXE capability to analyze very low mass samples together without any sample pre-treatment (which may be a source of contamination) makes it quite useful for the analysis of the aerosol collected in remote areas, such as the Antarctica plateau, Arctic areas or high-altitude sampling sites.

It is important to remember that PIXE provide only part of the desired information with regard to the chemical composition (anyway very important). PIXE researchers should not limit themselves to PIXE or IBA analyses, but try to diversify their activities by performing also other chemical and/or physical and optical measurements and to establish collaborations with other groups (chemists, geologists, physicists, etc.). It is also important to participate to all the phases of cross-disciplinary projects regarding urban air quality, climate research, ecology, meteorology and epidemiology.

Acknowledgements Some of the cited studies were supported by INFN (Istituto Nazionale di Fisica Nucleare), under the NUMEN, MASAI, MANIA, TRACCIA Projects, and by the LIFE + (ENV/ES/584) EU Project. I want to thank PierAndrea Mandò, Silvia Nava, Giulia Calzolai, Massimo Chiari (University and INFN, Florence), Roberta Vecchi (University of Milan) and Paolo Prati (University of Genoa) who have worked hard to make possible the development of the activities on aerosol science at the LABEC laboratory.

Open Access This article is licensed under a Creative Commons Attribution 4.0 International License, which permits use, sharing, adaptation, distribution and reproduction in any medium or format, as long as you give appropriate credit to the original author(s) and the source, provide a link to the Creative Commons licence, and indicate if changes were made. The images or other third party material in this article are included in the article's Creative Commons licence, unless indicated otherwise in a credit line to the material. If material is not included in the article's Creative Commons licence and your intended use is not permitted by statutory regulation or exceeds the permitted use, you will need to obtain permission directly from the copyright holder. To view a copy of this licence, visit http://creativecommons.org/licenses/by/4.0/.

\section{References}

1. IPCC, Climate change, in The Physical Science Basis. Contribution of Working Group I to the Fifth Assessment Report of the Intergovernmental Panel on Climate Change, ed. by T.F. Stocker, D. Qin, G.K. Plattner, M. Tignor, S.K. Allen, J. Boschung, A. Nauels, Y. Xia, V. Bex, P.M. Midgley (Cambridge University Press, Cambridge, 2013)

2. HEI Review Panel on Ultrafine Particles, Understanding the Health Effects of Ambient Ultrafine Particles. HEI Perspectives 3 (Health Effects Institute, Boston, 2013)

3. S.A.E. Johansson, J.L. Campbell, K.G. Malmqvist, Particle-Induced X-Ray Emission Spectroscopy (Wiley, London, 1995)

4. W. Maenhaut, K. Malmqvist, in Handbook of X-ray Spectrometry, ed. by R.E. Van Grieken, A.A. Markowicz (Marcel Dekker, Antwerp, 2001), pp. 761-771

5. X. Querol, A. Alastuey, S. Rodríguez, F. Plana, E. Mantilla, C.R. Ruiz, Atmos. Environ. 35, 845 (2001) 
6. R. Traversi, S. Becagli, F. Lucarelli, S. Nava, F. Rugi, M. Severi, R. Udisti, Nucl. Instrum. Methods B 318, 130 (2014)

7. K. Van Meel, B. Horemans, A. Krata, L. Bencs, A.J. Buczyiiska, A.C. Dirtu, A. Worobiec, R. Van Grieken, Environ. Chem. Lett. 8, 157 (2010)

8. K.D. Perry, S.S. Cliff, P. Jimenez-Cruz, J. Geophys. Res. 109(D23S), 28 (2004)

9. P. Paatero, U. Tapper, Environmetrics 5, 111 (1994)

10. A. D’Alessandro, F. Lucarelli, P.A. Mandò, G. Marcazzan, S. Nava, P. Prati, G. Valli, R. Vecchi, A. Zucchiatti, J. Aerosol Sci. 34, 243 (2003)

11. W. Maenhaut, R. Hillamo, T. Mäkelä, J.L. Jaffrezo, M.H. Bergin, C.I. Davidson, Nucl. Instrum. Methods B 109-110, 482 (1996)

12. S. Nava, S. Becagli, G. Calzolai, M. Chiari, F. Lucarelli, P. Prati, R. Traversi, R. Udisti, G. Valli, R. Vecchi, Atmos. Environ. 60, 444 (2012)

13. F. Marino, G. Calzolai, S. Caporali, E. Castellano, M. Chiari, F. Lucarelli, V. Maggi, S. Nava, M. Sala, R. Udisti, Nucl. Instrum. Methods B 266, 2396 (2008)

14. G. Calzolai, M. Chiari, F. Lucarelli, S. Nava, S. Portarena, Nucl. Instrum. Methods Phys. Res. B 268, 1540 (2010)

15. F. Lucarelli, S. Nava, G. Calzolai, M. Chiari, M. Giannoni, R. Traversi, R. Udisti, Nucl. Instrum. Methods B 363, 105 (2015)

16. S.A.E. Johansson, J.L. Campbell, PIXE: a Novel Tech- nique for Elemental Analysis (Wiley, Chichester, 1988)

17. P.A. Mandò, PIXE (Particle-induced X-ray emission), in Encyclopedia of Analytical Chemistry, ed. by R.A. Meyers (Wiley, Chichester, 2000), pp. 12708-12740

18. T. Calligaro, J.-C. Dran, B. Moignard, J. Salomon, Development of an external beam nuclear microprobe on the AGLAE facility of the Louvre Museum. Nucl. Instrum. Methods B161-163, 328 (2000)

19. C. Tomasi, S. Fuzzi, A. Kokhanovsky (eds.), Atmospheric Aerosols, Lige Cycles and Effects on Air Quality and Climate (Wiley, Hoboken, 2017)

20. J.H. Seinfeld, Atmospheric Chemistry and Physics of Air Pollution (Wiley, New York, 1986)

21. H.B. Singh, Composition, Chemistry, and Climate of the Atmosphere (Wiley, New York, 1995)

22. R.L. Maynard, C.V. Howard (eds.), Particulate Matter: Properties and Effects Upon Health (BIOS Scientific Publishers, Oxford, 1999)

23. I. Tegen, I. Fung, Contribution to the atmospheric mineral aerosol load from land surface modification. J. Geophys. Res. 100, 18707-18726 (1995)

24. WHO, Air Quality Guidelines for Europe, European Series (n. 91) (WHO Regional Publications, Copenhagen, 2000)

25. R.J. Charlson, M.J. Pilat, Climate: the influence of aerosols. J. Appl. Meteorol. 8, 1001 (1969)

26. I. Tegen, P. Hollrig, M. Chin, I. Fung, D. Jacob, J. Penner, Contribution of different aerosol species to the global aerosol extinction optical thickness: estimates from model results. J. Geophys. Res. 102, 23895-23915 (1997)

27. J.T. Houghton, Y. Ding, D.J. Griggs, M. Noguer, P.J. van der Linden, X. Dai, K. Maskell, C.A. Johnson (eds.), Climate Change 2001: The Scientific Basis (Cambridge University Press, Cambridge, 2001)

28. S.E. Schwartz, M.O. Andreae, Uncertainty in climate change caused by aerosols. Science 272, 1121 (1996)

29. P. Del Carmine, F. Lucarelli, P.A. Mandò, G. Moscheni, A. Pecchioli, J.D. MacArthur, Nucl. Instrum. Methods B 45, 341 (1990)

30. F. Lucarelli, G. Calzolai, M. Chiari, M. Giannoni, D. Mochi, S. Nava, L. Carraresi, Nucl. Instrum. Methods B 318, 55 (2014)

31. S. Becagli, C. Ghedini, S. Peeters, A. Rottiers, R. Traversi, R. Udisti, M. Chiari, A. Jalba, S. Despiau, U. Dayan, A. Temara, Atmos. Environ. 45, 6788 (2011)

32. P. Panteliadis, T. Hafkenscheid, B. Cary, E. Diapouli, A. Fischer, O. Favez, P. Quincey, M. Viana, R. Hitzenberger, R. Vecchi, D. Saraga, J. Sciare, J.L. Jaffrezo, A. John, J. Schwarz, M. Giannoni, J. Novak, A. Karanasiou, P. Fermo, W. Maenhaut, Atmos. Meas. Tech. 8, 779 (2015)

33. C.A. Belis, F. Karagulian, F. Amato, M. Almeida, P. Artaxo, D.C.S. Beddows, V. Bernardoni, M.C. Bove, S. Carbone, D. Cesari, D. Contini, E. Cuccia, E. Diapouli, K. Eleftheriadis, O. Favez, I. El Haddad, R.M. Harrison, S. Hellebust, J. Hovorka, E. Jang, H. Jorquera, T. Kammermeier, M. Karl, F. Lucarelli, D. Mooibroek, S. Nava, J.K. Nø, P. Pokorna, P. Prati, A.S.H. Prevot, U. Quass, X. Querol, D. Saraga, J. Sciare, A. Sfetsos, G. Valli, R. Vecchi, M. Vestenius, E. Yubero, P.K. Hopke, Atmos. Environ. 123, 240 (2015)

34. F. Amato, A. Alastuey, A. Karanasiou, F. Lucarelli, S. Nava, G. Calzolai, M. Severi, S. Becagli, V. Gianelle, C. Colombi, C. Alves, D. Custódio, T. Nunes, M. Cerqueira, C. Pio, K. Eleftheriadis, E. Diapouli, C. 
Reche, M.C. Minguillón, M. Manousakas, T. Maggos, S. Vratolis, R.M. Harrison, X. Querol, Atmos. Chem. Phys. 16, 3289 (2016)

35. F. Lucarelli, M. Chiari, G. Calzolai, M. Giannoni, S. Nava, R. Udisti, M. Severi, X. Querol, F. Amato, C. Alves, K. Eleftheriadis, Nucl. Instrum. Methods B 363, 92 (2015)

36. E. Diapouli, M.I. Manousakas, S. Vratolis, V. Vasilatou, S. Pateraki, K.A. Bairachtari, X. Querol, F. Amato, A. Alastuey, A. Karanasiou, F. Lucarelli, S. Nava, G. Calzolai, V.L. Gianelle, C. Colombi, C. Alves, D. Custódio, C. Pio, C. Spyrou, G.B. Kallos, K. Eleftheriadis, Atmos. Chem. Phys. 17, 3673 (2017)

37. T. Moreno, A. Karanasiou, F. Amato, F. Lucarelli, S. Nava, G. Calzolai, M. Chiari, E. Coz, B. Artiano, J. Lumbreras, R. Borge, E. Boldo, C. Linares, A. Alastuey, X. Querol, W. Gibbons, Atmos. Environ. 68, 33 (2013)

38. M. Dall'Osto, X. Querol, F. Amato, A. Karanasiou, F. Lucarelli, S. Nava, G. Calzolai, M. Chiari, Atmos. Chem. Phys. 13, 4375 (2013)

39. L.R. Crilley, F. Lucarelli, W.J. Bloss, R.M. Harrison, D.C. Beddows, G. Calzolai, S. Nava, G. Valli, V. Bernardoni, R. Vecchi, Environ. Pollut. 220, 766-778 (2017)

40. T. Moreno, T. Kojima, F. Amato, F. Lucarelli, J. de la Rosa, G. Calzolai, S. Nava, M. Chiari, A. Alastuey, X. Querol, W. Gibbons, Atmos. Chem. Phys. 13, 1411 (2013)

41. A.M. Taiwo, D.C.S. Beddows, G. Calzolai, R.M. Harrison, F. Lucarelli, S. Nava, Z. Shi, G. Valli, R. Vecchi, Sci. Total Environ. 490, 488 (2014)

42. J. Crespo, E. Yubero, J.F. Nicolas, F. Lucarelli, S. Nava, M. Chiari, G. Calzolai, J. Hazard. Mater. 241-242, $82(2012)$

43. X. Querol, W. Aas, F. Lucarelli, N. Pérez, T. Moreno, F. Cavalli, H. Areskoug, V. Balan, M. Catrambone, D. Ceburnis, J.C. Cerro, S.C.L. Gevorgyan, C. Hueglin, K. Imre, J.L. Jaffrezo, S.R. Leeson, N. Mihalopoulos, M. Mitosinkova, C.D. O’Dowd, J. Pey, J. Putaud, V. Riffault, A. Ripoll, J. Sciare, K. Sellegri, G. Spindler, K.E. Yttri, Atmos. Chem. Phys. 16, 6107 (2016)

44. M. Marconi, D.M. Sferlazzo, S. Becagli, C. Bommarito, G. Calzolai, M. Chiari, A. di Sarra, C. Ghedini, J.L. Gomez-Amo, F. Lucarelli, D. Meloni, F. Monteleone, S. Nava, G. Pace, S. Piacentino, F. Rugi, M. Severi, R. Traversi, R. Udisti, F. Meloni, G. Less Monteleone, S. Pace, F. Piacentino, M. Rugi, M. Severi, R. Traversi, R. Udisti, Atmos. Chem. Phys. 14, 2039 (2014)

45. L. Matassoni, G. Pratesi, D. Centioli, F. Cadoni, F. Lucarelli, S. Nava, P. Malesani, J. Environ. Monit. 13, 732 (2011)

46. R.R. Draxler, G.D. Rolph, HYSPLIT Model, NOAA ARL READY. 2003. http://www.arl.noaa.gov/ready/ hysplit4.html. Accessed 26 June 2020

47. S. Rodríguez, G. Calzolai, M. Chiari, S. Nava, M.I. García, J. Lopez-Solano, C. Marrero, J. Lopez-Darias, E. Cuevas, S. Alonso-Perez, N. Prats, F. Amato, F. Lucarelli, X. Querol, Atmos. Environ. 223, 117186 (2020)

48. F. Marino, G. Calzolai, S. Caporali, E. Castellano, M. Chiari, F. Lucarelli, V. Maggi, S. Nava, M. Sala, R. Udisti, Nucl. Instrum Methods B266, 2396 (2008)

49. EPICA Community Members, Eight glacial cycles from an Antarctic ice core. Nature 429, 623 (2004) 